\title{
ERRATUM
}

\section{Erratum to: Polypyrrole@NiCo hybrid nanotube arrays as high performance electrocatalyst for hydrogen evolution reaction in alkaline solution}

\author{
Shenghua Ye, Gaoren Li (ه) \\ MOE Laboratory of Bioinorganic and Synthetic Chemistry, KLGHEI of Environment and Energy Chemistry, School of Chemistry and Chemical \\ Engineering, Sun Yat-sen University, Guangzhou 510275, China
}

(C) Higher Education Press and Springer-Verlag GmbH Germany, part of Springer Nature 2019

Erratum to: Frontiers of Chemical Science and Engineering, 2018, 12(3): 473-480.

DOI https://doi.org/10.1007/s11705-018-1724-9

Figure 2(b) on Page 476: It has come to our attention that the data of (i) Co NTAs in Fig. 2(b) is not correct, because we imported the same group of data of PPy@NiCo HNTAs accidentally while plotting with Origin. The corrected Fig. 2(b) is shown below. The data analysis and conclusions are not affected by this unintentional error.

The text on Page 474: The sentence of "Figures $2 b(i)$ and $2 b(i i)$ show Co $2 p_{1 / 2}$ peak of NiCo NTAs negatively shifts $\sim 0.4 \mathrm{eV}$ relative to that of Co NTAs" is not correct, and it should be revised as below: "Figures $2 \mathrm{~b}(\mathrm{i})$ and $2 \mathrm{~b}$ (ii) show Co $2 \mathrm{p}_{3 / 2}$ peak of NiCo NTAs negatively shifts $\sim 0.35 \mathrm{eV}$ relative to that of Co NTAs."

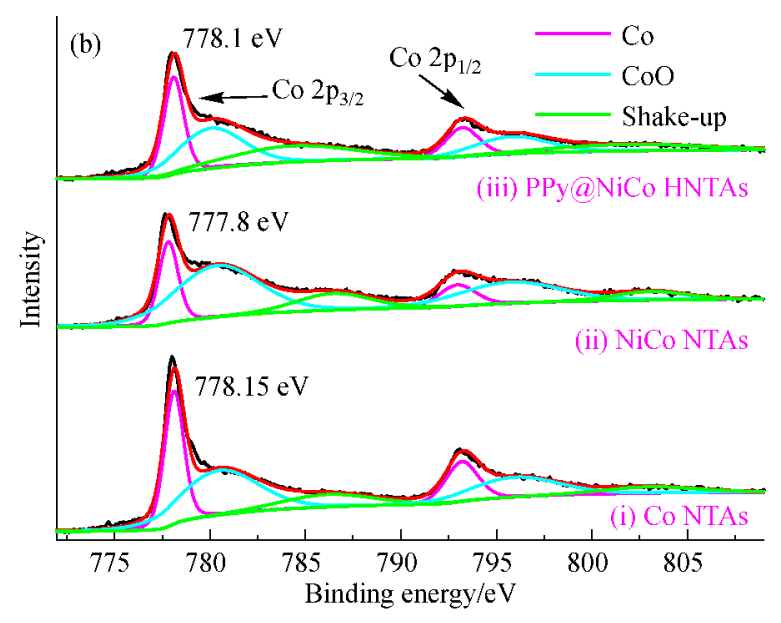

Fig. 2(b)

The online version of the original article can be found at https://ink.springer.com/article/10.1007/s11705-018-1724-9 